\title{
Isolation of intact vacuoles from Arabidopsis rosette leaf-derived protoplasts
}

\author{
Stéphanie Robert ${ }^{1}$, Jan Zouhar ${ }^{1,2}$, Clay Carter $^{1,3} \&$ Natasha Raikhel $^{1}$ \\ ${ }^{1}$ Department of Botany and Plant Sciences, Institute for Integrative Genome Biology, Center for Plant Cell Biology, University of California, Riverside, California 92521, \\ USA. Present addresses: ${ }^{2}$ Departamento de Genética Molecular de Plantas, Centro Nacional de Biotecnología, Consejo Superior de Investigaciones Científicas, Madrid \\ E-28049, Spain. ${ }^{3}$ Department of Biology, University of Minnesota, Duluth, Minnesota 55812, USA. Correspondence should be addressed to N.R. (nraikhel@ucr.edu).
}

Published online 22 February 2007; doi:10.1038/nprot.2007.26

\begin{abstract}
Vacuoles are very prominent compartments within plant cells, and understanding of their function relies on knowledge of their content. Here, we present a simple vacuole purification protocol that was successfully used for large-scale isolation of vacuoles, free of significant contamination from other endomembrane compartments. This method is based on osmotic and thermal disruption of mesophyl-derived Arabidopsis protoplasts, followed by a density gradient fractionation of the cellular content. The whole procedure, including protoplast isolation, takes approximately $6 \mathrm{~h}$.
\end{abstract}

\section{INTRODUCTION}

Large-scale isolation and characterization of cellular organelles offers excellent opportunities in plant systems biology ${ }^{1}$. Detailed qualitative and quantitative knowledge of the composition of a particular organelle allows for investigation of subcellular pathways through the identification of novel protein components and the analysis of cellular sinks. This also facilitates detailed comparative studies between species or between mutant and wild-type plants. In contrast to some organelles, such as mitochondria and chloroplasts, that are relatively easy to obtain in a pure form ${ }^{2,3}$, plant vacuoles are extremely fragile, and their isolation using conventional tissue homogenization and fractionation schemes can be remarkably challenging and often results in a subcellular fraction without the same properties as intact mature vacuoles ${ }^{4}$. The first successful technique to overcome these difficulties was based on protoplast isolation and subsequent gentle release of vacuoles by osmotic shock $^{5,6}$. Later large-scale isolation protocols employed gradient fractionation of osmotically released organelles ${ }^{7,8}$, and the method was further optimized by application of both osmotic and thermal shocks to the isolated protoplasts ${ }^{9,10}$. As an alternative to the protoplast methods, which are applicable only to relatively soft tissues, vacuoles can be isolated by slicing the plant material and releasing contents into a medium with a perfectly adjusted osmoticum $^{11}$. In subsequent studies, numerous vacuolar constituents have been determined, including sugars and amino acids ${ }^{12}$, hydrolases $^{13}$ and ions ${ }^{14}$.
The increasing impact of proteomic studies on plant biology ${ }^{15,16}$ has triggered renewed interest in organelle purification and led to two independent proteomic studies focused on intact vacuoles derived from different plant tissues ${ }^{17,18}$. In contrast to a relatively intricate protocol describing intact vacuole purification from an Arabidopsis cell suspension ${ }^{18}$, we present a simple, reliable method for vacuole isolation from Arabidopsis leaf mesophyl protoplasts in great detail ${ }^{17}$. This protocol is based on one-step Ficoll gradient fractionation of osmotically and thermally lysed protoplasts under simple chemical conditions. This method has been used successfully in our laboratory for biochemical characterization of vacuolar contents using both proteomics and immunological approaches. The focus of this protocol on vegetative tissues has allowed for comparative studies of a mutant plant line that was affected in terms of vacuolar protein processing and degradation ${ }^{19}$. Therefore, this protocol provides an exceptional opportunity for comparative studies between multiple plant lines without generation of stable cell suspension cultures.

\section{Procedural comments}

This protocol is designed to be performed within $1 \mathrm{~d}$. It consists of two steps, which include the isolation of the protoplast followed by a gradient fractionation. The buffers should be made fresh, and the plant tissues cannot be frozen. It is recommended that the experimenter wear gloves during the whole procedure.

\section{MATERIALS}

REAGENTS

- $\mathrm{CaCl}_{2} \cdot 2 \mathrm{H}_{2} \mathrm{O}$ (Fisher, cat. no. C614)

- Cellulase Onozuka R-10 (1.0 U mg ${ }^{-1}$ ) (Serva, Heidelberg, Germany, cat. no.

16419) ! CAUTION Harmful; avoid inhalation and contact with skin.

-EDTA (J.T. Baker, cat. no. 893) (see REAGENT SETUP)

- Ficoll (Sigma, cat. no. F4375)

- Macerozyme R-10 (0.55 U mg ${ }^{-1}$ ) (Serva, Heidelberg, Germany, cat. no.

28032) ! CAUTION Harmful; avoid inhalation and contact with skin.

- Mannitol (Fisher, cat. no. M120) (see REAGENT SETUP)

- $\beta$-Mercaptoethanol (Sigma, cat. no. M3148) ! CAUTION Toxic; avoid

inhalation, ingestion or contact with skin, eyes or mucous membranes.

Dangerous for the environment.

-2-(N-morpholino)ethanesulfonic acid (VWR, cat. no. EM6110)

(see REAGENT SETUP)
- $\mathrm{Na}_{2} \mathrm{HPO}_{4} \cdot 7 \mathrm{H}_{2} \mathrm{O}$ (Sigma, cat. no. S9390)

$\cdot \mathrm{NaH}_{2} \mathrm{PO}_{4} \cdot \mathrm{H}_{2} \mathrm{O}$ (Sigma, cat. no. S9638)

- Neutral Red dye (Sigma, cat. no. N7005) (see REAGENT SETUP)

- Acetic acid

- Solid $\mathrm{NaOH}$

- Milli-Q water

$\cdot \mathrm{KOH}(1 \mathrm{M})$

- Lysis buffer (see REAGENT SETUP)

- Chloroform

-Wash buffer (see REAGENT SETUP)

- Protoplast enzyme solution (see REAGENT SETUP)

- Vacuole buffer (see REAGENT SETUP)

EQUIPMENT

- Allegra 6 benchtop centrifuge (Beckman Coulter, cat. no. 366802) 
- Axioskop 40 Pol upright microscope (Zeiss)

-50-ml BD Falcon centrifuge tubes, polypropylene, conical bottom, sterile

(BD Bioscience; VWR, cat. no. 21008-178)

- Benchtop open air Excella shaker model E1 (New Brunswick scientific)

- Cellector Tissue Sieve Thermo EC (150 mesh) (VWR, cat. no. 62399-872)

-GH-3.8 rotor, swinging bucket, 3,750 r.p.m., 3,200g (Beckman Coulter,

cat. no. 360581)

- $250 \mathrm{ml}$ Kimax flasks with side arm (Fisher, cat. no. 10-181D)

- $150 \mathrm{ml}$ Pyrex brand fleaker beaker (Fisher, cat. no. 02599)

- Pyrex $5 \mathrm{ml}$ reusable wide-tip serological pipettes, TD, color-coded, colored markings (Corning Inc., cat. no. 7078B-5)

-SW 40 Ti rotor, swinging bucket, $6 \times 14$ ml, 40,000 r.p.m., 285,000g

(Beckman Coulter, cat. no. 331302)

-Ultra-clear centrifugation tubes, $14 \mathrm{ml}, 14 \times 95 \mathrm{~mm}$ (Beckman Coulter, cat. no. 344060)

\section{REAGENT SETUP}

0.5 M EDTA Dissolve $74.45 \mathrm{~g}$ EDTA in $300 \mathrm{ml}$ Milli-Q water. Adjust $\mathrm{pH}$ to 8 with solid $\mathrm{NaOH}$. Add Milli-Q water until the total volume is $400 \mathrm{ml}$.

$30 \%$ (wt/vol) Ficoll Dissolve $4.5 \mathrm{~g}$ Ficoll in Milli-Q water to a total volume of $15 \mathrm{ml}$. Heat the solution carefully for several minutes in a $65^{\circ} \mathrm{C}$ water bath and vortex until completely dissolved. The Ficoll solution can be prepared $1 \mathrm{~d}$ ahead. $\Delta$ CRITICAL The 30\% Ficoll solution should not be exposed to excessive heat. Ficoll is difficult to dissolve, but heat the solution for a short time without boiling it.

$1 \mathrm{M}$ mannitol Dissolve $72.87 \mathrm{~g}$ mannitol in $400 \mathrm{ml}$ Milli-Q water.
$50 \mathrm{mM}$ MES, pH 5.6 Dissolve $1.07 \mathrm{~g}$ MES in $80 \mathrm{ml}$ Milli-Q water. Adjust $\mathrm{pH}$ to 5.6 with $1 \mathrm{M} \mathrm{KOH}$. Add Milli-Q water until the total volume is $100 \mathrm{ml}$. 0.1\% Neutral Red solution Mix $0.1 \mathrm{~g}$ Neutral Red, $200 \mu \mathrm{l} \%$ acetic acid and $50 \mu \mathrm{l}$ chloroform. Add Milli-Q water until the total volume is $100 \mathrm{ml}$. 0.2 M sodium phosphate, $\mathrm{pH} 7.5$ Mix $16 \mathrm{ml}$ solution $\mathrm{A}\left(27.6 \mathrm{~g} \mathrm{NaH}_{2} \mathrm{PO}_{4}\right.$. $\mathrm{H}_{2} \mathrm{O}$ per liter; $\left.0.2 \mathrm{M}\right)$ and $84 \mathrm{ml}$ solution $\mathrm{B}\left(53.65 \mathrm{~g} \mathrm{Na}_{2} \mathrm{HPO}_{4} \cdot 7 \mathrm{H}_{2} \mathrm{O}\right.$ per liter; $0.2 \mathrm{M}$ ).

0.2 M sodium phosphate, pH 8.0 Mix $5.3 \mathrm{ml}$ solution A (27.6 g NaH${ }_{2} \mathrm{PO}_{4}$. $\mathrm{H}_{2} \mathrm{O}$ per liter; $\left.0.2 \mathrm{M}\right)$ and $94.7 \mathrm{ml}$ solution $\mathrm{B}\left(53.65 \mathrm{~g} \mathrm{Na}_{2} \mathrm{HPO}_{4} \cdot 7 \mathrm{H}_{2} \mathrm{O}\right.$ per liter; $0.2 \mathrm{M}$ ).

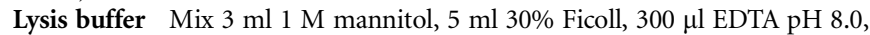
$375 \mu \mathrm{l} 0.2 \mathrm{M}$ sodium phosphate $\mathrm{pH} 8.0$ and $75 \mu \mathrm{l} \mathrm{Neutral} \operatorname{Red}^{20}$. Add Milli-Q water until the total volume is $15 \mathrm{ml}$. Keep at $37^{\circ} \mathrm{C}$.

Vacuole buffer Mix $4.5 \mathrm{ml} 1 \mathrm{M}$ mannitol, $250 \mu \mathrm{l} 0.2 \mathrm{M}$ sodium phosphate $\mathrm{pH} 7.5$ and $40 \mu \mathrm{l} 0.5 \mathrm{M}$ EDTA pH 8.0. Add Milli-Q water until the total volume is $10 \mathrm{ml}$. Keep on ice.

4\% Ficoll solution Mix $4.5 \mathrm{ml}$ vacuole buffer and $3 \mathrm{ml}$ lysis buffer. Keep at room temperature $\left(\sim 25^{\circ} \mathrm{C}\right)$.

Wash buffer Mix $60 \mathrm{ml} 1 \mathrm{M}$ mannitol and $30 \mathrm{ml} 50 \mathrm{mM}$ MES pH 5.6. Add Milli-Q water until the total volume is $150 \mathrm{ml}$.

Protoplast enzyme solution Dissolve $0.3 \mathrm{~g}$ cellulase, $0.3 \mathrm{~g}$ macerozyme, $0.12 \mathrm{~g}$ $\mathrm{CaCl}_{2} \cdot 2 \mathrm{H}_{2} \mathrm{O}$ in $30 \mathrm{ml}$ wash buffer. Keep at $37^{\circ} \mathrm{C}$ with occasional vortexing until the enzymes are completely dissolved. Add $10.5 \mu \mathrm{l} \beta$-mercaptoethanol. ! CAUTION $\beta$-Mercaptoethanol is toxic and dangerous for the environment. Handle using appropriate safety equipment and measures. Cellulase and macerozyme are harmful.

\section{PROCEDURE}

Plant material

1| Remove rosette leaves from 35-day-old Arabidopsis plants. The plants should be grown under short-day conditions (8 h light) at $18{ }^{\circ} \mathrm{C}$ in small pots, one plant per pot. ? TROUBLESHOOTING

\section{Protoplast isolation}

2| Collect no more than $2 \mathrm{~g}$ rosette leaf tissue.

3| Cut the leaves into $2 \mathrm{~mm}$ strips using a razor blade.

4| Place the processed leaves and $30 \mathrm{ml}$ protoplast enzyme solution into a 250-ml Kimax flask with side arm and apply vacuum for $10 \mathrm{~min}$.

I CAUTION $\beta$-Mercaptoethanol is toxic and dangerous for the environment. Cellulase and macerozyme are harmful.

5| Cover the flask openings with Parafilm and incubate the tissues with the protoplast enzyme solution for $4 \mathrm{~h}$ on a benchtop open air Excella shaker model E1 in the dark. Shake at 70 r.p.m.

6| Wash the protoplasts by straining through a Cellector Tissue Sieve Thermo EC into a 150-ml Pyrex brand fleaker beaker (150 mesh). Rinse the Cellector Tissue Sieve Thermo EC gently with $5 \mathrm{ml}$ wash buffer.

7| Transfer the protoplasts carefully into a 50-mL BD Falcon centrifuge tube.

8| Rinse the fleaker with an additional $5 \mathrm{ml}$ wash buffer.

9| Spin down the protoplasts in an Allegra 6 benchtop centrifuge at $80 \mathrm{~g}$ at $20{ }^{\circ} \mathrm{C}$ for $20 \mathrm{~min}$.

10| Remove and discard the supernatant using a Falcon disposable polystyrene serological pipette.

11| Gently re-suspend the pellet in approximately $30 \mathrm{ml}$ wash buffer.

12| Spin (as described in Step 9) and wash once more with wash buffer to remove protoplasting enzymes.

13| Check the isolated protoplasts under the light microscope. You may wish to keep some unlysed protoplasts for comparative/enrichment analysis. Proceed with the remainder as described below.

\section{Vacuole isolation}

14| Add $10.5 \mathrm{ml}$ pre-warmed lysis buffer to the protoplasts using a Falcon disposable polystyrene serological pipette. 
15| Re-suspend well, yet gently, by pipetting 5-8 times up and down using a 5-ml Pyrex reusable wide-tip serological pipette.

16| Wait for $2 \mathrm{~min}$.

17| Inspect the protoplast disruption and the vacuole release under the light microscope (Fig. 1).

18| Transfer $5 \mathrm{ml}$ of the solution into an ultra-clear centrifugation tube (two tubes per sample) using a $5 \mathrm{ml}$ Pyrex reusable wide-tip serological pipette.

19| Overlay with $3 \mathrm{ml} 4 \%$ Ficoll solution using a $10 \mathrm{ml}$ Falcon disposable polystyrene serological pipette.

$\triangle$ CRITICAL STEP The layering of the gradient has to be done very carefully but quickly; try to avoid mixing the consecutive layers.

20| Layer $1 \mathrm{ml}$ ice-cold vacuole buffer on the top of the gradient.

$\triangle$ CRITICAL STEP The layering of the gradient has to be done very carefully but quickly; try to avoid mixing the consecutive layers.

21 Spin for $50 \mathrm{~min}$ at $71,000 \mathrm{~g}$ at $10^{\circ} \mathrm{C}$ in an Optima L-90K ultra-centrifuge using slow acceleration and slow deceleration settings.

22 Vacuoles should be visible as a pink layer on the interface between 0 and 4\% Ficoll. Remove them carefully using a pipette. ? TROUBLESHOOTING

23| Check the vacuoles for purity under the light microscope (Fig. 1).

? TROUBLESHOOTING

TIMING

Vacuole isolation can be performed in approximately $6 \mathrm{~h}$.

? TROUBLESHOOTING

Troubleshooting advice can be found in Table 1.

TABLE 1 | Troubleshooting table.

\begin{tabular}{llll}
\hline Step & Problem & Possible reasons & Solution \\
\hline 1 & No vacuoles detected at the interface & The amount of tissue was exceeded & Use $2 \mathrm{~g}$ of leaves \\
22 & No vacuoles detected at the interface & The Ficoll stock solution was overheated & Avoid excessive heat \\
23 & A few vacuoles detected at the interface & The plant material has aged and is senescing & Use fresh, 35-day-old rosette leaves
\end{tabular}

\section{ANTICIPATED RESULTS}

The typical amount of protein found in the final vacuolar sample is $50 \mu \mathrm{g}$. The purity of the vacuole fraction extracted according to this protocol has been studied and discussed extensively ${ }^{17,19,21}$. The presence of different markers of the endomembrane system and other organelles in the vacuolar fraction has been examined using immunoblot analysis. The vacuolar markers AtALEU, $\gamma$-TIP and SYP22 were enriched in the vacuolar fractions, but AtVPS45 (TGN), SYP21 (PVC), AtSEC12 (ER) and Hsp93 (chloroplasts) were not present at a detectable level in the vacuolar fractions, indicating that the fractions were not contaminated with these organelles.

ACKNOWLEDGMENTS This work was supported by the U.S. Department of Energy, Division of Energy Biosciences (Grant DE-FG02-02ER15295 to N.R.).

COMPETING INERESTS STATEMENT The authors declare that they have no competing financial interests.

Published online at http://www.natureprotocols.com

Reprints and permissions information is available online at http://npg.nature.com/ reprintsandpermissions

1. Girke, T., Ozkan, M., Carter, D. \& Raikhel, N.V. Towards a modeling infrastructure for studying plant cells. Plant Physiol. 132, 410-414 (2003).

2. Millar, A.H., Sweetlove, L.J., Giege, P. \& Leaver, C.J. Analysis of the Arabidopsis mitochondrial proteome. Plant Physiol. 127, 1711-1727 (2001).
3. Fitzpatrick, L.M. \& Keegstra, K. A method for isolating a high yield of Arabidopsis chloroplasts capable of efficient import of precursor proteins. Plant J. 27, 59-65 (2001).

4. Matile, P. \& Wiemken, A. Vacuoles and spherosomes. Methods Enzymol. 31, 572-578 (1974).

5. Cocking, E.C. A method for the isolation of plant protoplasts and vacuoles. Nature 187, 962-963 (1960).

6. Strobel, G.A. \& Hess, W.M. Evidence for the presence of the toxin-binding protein on the plasma membrane of sugarcane cells. Proc. Natl. Acad. Sci. USA 71 1413-1417 (1974).

7. Wagner, G.J. \& Siegelman, H.W. Large-scale isolation of intact vacuoles and isolation of chloroplasts from protoplasts of mature plant-tissues. Science 190, 1298-1299 (1975). 
8. Boller, T. \& Kende, H. Hydrolytic enzymes in the central vacuole of plant-cells. Plant Physiol. 63, 1123-1132 (1979).

9. Sonnewald, U., Brauer, M., von Schaewen, A., Stitt, M. \& Willmitzer, L. Transgenic tobacco plants expressing yeast-derived invertase in either the cytosol, vacuole or apoplast: a powerful tool for studying sucrose metabolism and sink/source interactions. Plant J. 1, 95-106 (1991).

10. Gomez, L. \& Chrispeels, M.J. Tonoplast and soluble vacuolar proteins are targeted by different mechanisms. Plant Cell 5, 1113-1124 (1993).

11. Leigh, R.A. \& Branton, D. Isolation of vacuoles from root storage tissue of Beta vulgaris L. Plant Physiol. 58, 656-662 (1976).

12. Wagner, G.J. Content and vacuole/extravacuole distribution of neutral sugars, free amino acids, and anthocyanin in protoplasts. Plant Physiol. 64, 88-93 (1979).

13. Nishimura, M. \& Beevers, H. Hydrolases in vacuoles from castor bean endosperm. Plant Physiol. 62, 44-48 (1978).

14. Granstedt, R.C. \& Huffaker, R.C. Identification of the leaf vacuole as a major nitrate storage pool. Plant Physiol. 70, 410-413 (1982).
15. Canovas, F.M. et al. Plant proteome analysis. Proteomics 4, 285-298 (2004).

16. Rossignol, M. et al. Plant proteome analysis: a 2004-2006 update. Proteomics 6 , 5529-5548 (2006).

17. Carter, C. et al. The vegetative vacuole proteome of Arabidopsis thaliana reveals predicted and unexpected proteins. Plant Cell 16, 3285-3303 (2004).

18. Shimaoka, T. et al. Isolation of intact vacuoles and proteomic analysis of tonoplast from suspension-cultured cells of Arabidopsis thaliana. Plant Cell Physiol. 45, 672-683 (2004).

19. Rojo, E., Zouhar, J., Carter, C., Kovaleva, V. \& Raikhel, N.V. A unique mechanism for protein processing and degradation in Arabidopsis thaliana. Proc. Natl. Acad. Sci. USA 100, 7389-7394 (2003).

20. Dubrovsky, J.G. et al. Neutral red as a probe for confocal laser scanning microscopy studies of plant roots. Ann. Bot. (Lond) 97, 1127-1138 (2006).

21. Ahmed, S.U. et al. The plant vacuolar sorting receptor AtELP is involved in transport of $\mathrm{NH}(2)$-terminal propeptide-containing vacuolar proteins in Arabidopsis thaliana. J. Cell. Biol. 149, 1335-1344 (2000). 